\title{
CATALYTIC PYROLYSIS OF AUTOMOBILE SHREDDER RESIDUE
}

\author{
Gregory G. Arzoumanidis, Michael J. McIntosh, Con f $950801--12$ \\ Eric J. Steffensen, Matthew J. McKee, and Timothy Donahugh \\ Energy Systems Division, Building 362 \\ Argonne National Laboratory \\ Argonne, Illinois 60439
}

Keywords: Catalytic Pyrolysis, Plastics, Automobile Recycling

\section{INTRODUCTION}

In the United States, approximately 10 million automobiles are scrapped and shredded each year. The mixture of plastics and other materials remaining after recovery of the metals is known as Automobile Shredder Residue (ASR). In 1994, about 3.5 million tons of ASR was produced and disposed of in landfills. However, environmental, legislative, and economic considerations are forcing the industry to search for recycling or other alternatives to disposal $(1,2)$.

Numerous studies have been done relating the ASR disposal problem to possible recycling treatments such as pyrolysis, gasification, co-liquefaction of ASR with coal, chemical recovery of plastics from ASR (3), catalytic pyrolysis (4), reclamation in molten salts (5), and vacuum pyrolysis (6). These and other possibilities have been studied intensively, and entire symposia have been devoted to the problem (3). Product mix, yields, toxicology issues, and projected economics of conceptual plant designs based on experimental results are among the key elements of past studies. Because the kinds of recycling methods that may be developed, along with their ultimate economic value, depend on a very large number of variables, these studies have been open-ended. It is hoped that it may be useful to explore some of these previously studied areas from fresh perspectives. One such approach, currently under development at Argonne National Laboratory, is the catalytic pyrolysis of ASR.

\section{EXPERIMENTAL METHOD}

To elininate variability due to nonuniform sampling, testing was begun using a "synthetic ASR" made up from pure materials on the basis of a best estimate of the inert-free ASR composition (Table 1). For the catalytic studies, pyrolysis occurs in a ceramic tube reactor inserted into the 30-cm heating zone of an electric furnace. The ASR is positioned in the reactor by means of an inconnel sample holder. Time/temperature profile is controlled by microprocessor. The majority of experiments are conducted using the profile shown in Figure 1. Faster rates of pyrolysis correspond to the profile in Figure 2.

Liquids are collected in a series of three condensers, the first water-cooled, the others cooled by glycol at $-20^{\circ} \mathrm{C}$. Liquids are analyzed by GC/MS. Product gas samples are collected on-line in steel containers and analyzed by comparison with GC standards, using a $25-\mathrm{m} \times 0.53$ $\mathrm{mm}$ fused silica column coated by Poraplot $U$, available from Chrompack. The gas mixtures are further analyzed by FTIR.

For kinetic studies, a smaller tube and a furnace with a $15-\mathrm{cm}$ heating zone are used. The ASR sample is usually $10 \mathrm{gm}$. The reactor weight is continuously monitored by a sensitive transducer. The weight increase of a condenser is monitored by a second transducer. The time/temperature profile inside the reactor can be more accurately controlled in this smaller system. The profile, giving the results presented below, was ramped from ambient to $700^{\circ} \mathrm{C}$ in $60 \mathrm{~min}$ and maintained at $700^{\circ} \mathrm{C}$ for $100 \mathrm{~min}$. With this equipment, a continuous time/mass profile is obtained of the reactor residue, liquids condensed, and gases produced.

\section{RESULTS}

Catalytic pyrolysis of synthetic ASR was conducted in the presence of several oxides, montmoriilonite, and ASR clar (Tab's 2). The amont of gases produced (determined by difference) varied within a rather narrow range. The amount of $\mathrm{CO}_{2}$ in the sample was determined by using an ascarite-filled trap. The total amount of $\mathrm{CO}_{2}$ from uncatalyzed reactions is usually 6$9 \%$ of the synthetic ASR weight. In one case, $18 \% \mathrm{CO}_{2}$ was obtained, but the pyrolysis was run in the presence of $\mathrm{Fe}_{3} \mathrm{O}_{4}$, and oxidation of carbon by the metal oxide is likely.

Three gas samples were obtained at three different temperatures during each experiment. The first sample was collected at $400-440^{\circ} \mathrm{C}$ pyrolysis temperature, the second at $500^{\circ} \mathrm{C}$, and the third at $650^{\circ} \mathrm{C}$. GC analyses of the first samples gave the distribution of gases shown in Table 3 . The relative amounts of each separate gaseous hydrocarbon in the table vary widely, showing the large effect of catalyst on gas yields. Despite this variability, certain trends are clear. Most interesting is the large amount of $\mathrm{CH}_{3} \mathrm{Cl}$ formed in the first sample, in one case as high as $90 \%$ of the gases. Because a preliminary survey of the pyrolysis literature yielded no reports of this phenomenon, we proceeded with caution despite positive GC and FTIR identification of $\mathrm{CH}_{3} \mathrm{Cl}$. Accordingly, experiments were conducted on synthetic ASR, with its only chlorine-containing 


\section{DISCLAIMER}

Portions of this document may be illegible in electronic image products. Images are produced from the best available original document. 
material, PVC, removed. These tests produced essentially no $\mathrm{CH}_{3} \mathrm{Cl}$. In these experiments, $\mathrm{CH}_{4}$ in the first gas sample was at its highest level $(23 \%)$. It was also found that addition of $\mathrm{Na}_{2} \mathrm{CO}_{3}$ to the pyrolysis reaction reduces $\mathrm{CH}_{3} \mathrm{Cl}$ formation and increases the level of $\mathrm{CH}_{4}$ in the first stage. Given these results, the information in Table 3 offers several clues concerning the mechanism and kinetics of ASR pyrolysis. These are discussed below. Interestingly, the relative amounts of the pyrolysis gases from the second $\left(500^{\circ} \mathrm{C}\right)$ and third $\left(650^{\circ} \mathrm{C}\right)$ samples do not change appreciably, as indicated in Table 4. Changes in the relative amounts of the gases during the duration of the pyrolysis are estimated in Figure 3. This illustrates the large effect of the pyrolysis time/ temperature profile on gas product distribution. Several investigators have noticed different product distributions under a variety of experimental conditions (2a). However, a direct effect of the profile is now clearly seen in the figure. This result raises the possibility that the distribution and composition of gaseous and liquid products can be manipulated by variation of the time/temperature profile. This possibility, which could be of economic importance, is now under investigation.

As shown in Table 2, the residual solids (char) yield varied with catalyst type but remained in the range of 23-33\% of the initial ASR weight. Lower levels of char yield translate into higher amounts of liquids, possibly an economically desirable effect. A number of binary oxides containing $\mathrm{ZnO}$ as one of the catalyst components appear to reduce the formation of char. Other additives (magnesium titanate, zirconate, $\mathrm{Fe}_{3} \mathrm{O}_{4}$, montmorilonite) do not yield results very different from the control run without catalyst. The effects of $\mathrm{CuO}$ and $\mathrm{TiO}_{2} \cdot \mathrm{SiO}_{2}$ also are marginal. In evaluating a commercial ASR recycling process, low cost is of foremost importance. Expensive catalysts, such as the binary oxides of Table 2, are not likely to prove directly useful. The incentive for studying these more expensive materials is to gain an understanding of possible effects, which may aid in the development of cheaper catalysts.

Two classes of liquids are formed by the pyrolysis of ASR. The organic class contains over 50 organic compounds, as analyzed by GC/MS, and the aqueous class contains water and water-soluble oxygenates, primarily acids and alcohols. Water may be physically present in the ASR or may be produced chemically by primary or secondary pyrolysis reactions (see discussion). Chlorine-containing compounds could not be detected by GC/MS in either liquid class. Production of chlorine-free liquid is a desirable feature of a commercial ASR reclamation process if the liquid is to be used as fuel. In this case, it is also desirable to increase the yield of the organic class of liquid. The effects of various catalysts and pyrolysis conditions on maximizing organic liquids are currently under investigation.

\section{DISCUSSION}

The pyrolysis of each separate ASR component has been extensively studied by numerous investigators, and mechanisms have been proposed (7). These mechanisms are polymer-structure-dependent and may differ within the same class of polymers. For example, thermal degradation of polyurethanes may occur by three different types of hydrogen transfer: $\mathrm{N}$ $\mathrm{H}, \alpha-\mathrm{CH}$, and $\beta-\mathrm{CH}$, depending on the exact monomeric and polymeric structure of the pyrolyzing material (8). It is generally recognized that pyrolysis in a highly reducing environment proceeds via a radical mechanism. Detailed discussion of these mechanisms is beyond the scope of this paper.

The mechanism of ASR pyrolysis is very complex. Single products (e.g., methane and other aliphatic hydrocarbons) may be formed via different mechanisms, depending on the type and structure of the polymer of origin. Therefore, it is difficult to present a unified mechanism by observation of pyrolysis products alone. An important consideration, however, is the range of different temperatures at which degradation begins for each type of polymer. Polyurethanes may start degrading just above $200^{\circ} \mathrm{C}$ (7). Removal of $\mathrm{HCl}$ from PVC takes place at a relatively low temperature, and it is completed almost before the degradation of the hydrocarbon backbone begins (9). Similar observations may be made for other reactions, such as decarboxylation of nylon, polyesters, polyurethanes and acrylics, formation of chemical water from wood and paper, etc. Thus, it is reasonable to assume that each polymer begins the pyrolysis process individually, based on its own structural and thermodynamic character.

One of the key roles of catalysts is to lower the decomposition temperature by lowering the activation energy for some reactions. A single catalyst will not cause the same decrease of activation energy for all reactions of all ASR components. It is likely the main reason for the wide variation of the relative amounts of products in the first gas sample (Table 3) is the variability of catalyst effects as the temperature reaches a level where the most facile reactions are fairly rapid. However, most of the ASR polymers, after losing such weak-link components as $\mathrm{CO}_{2}, \mathrm{HCl}$, and $\mathrm{H}_{2} \mathrm{O}$, revert to mostly hydrocarbon backbones, which likely are very similar. This probably is the reason for the limited variations in the product distribution of the second and third gas samples (Table 4).

From the above discussion, at least two distinct stages in the pyrolysis of ASR are hypothesized. The first stage ends at about $300^{\circ} \mathrm{C}$, and the second, in our case, continues up to 
$700^{\circ} \mathrm{C}$. Preliminary experiments suggest that most of the $\mathrm{CO}_{2}, \mathrm{CO}, \mathrm{H}_{2} \mathrm{O}, \mathrm{CH}_{3} \mathrm{Cl}$, and possibly some nitrogen-containing components are being released in the first stage. Significantly, these materials carry most of the hetero-atoms that may interfere with the overall quality of useful ASR pyrolysis products.

The formation of $\mathrm{CH}_{3} \mathrm{Cl}$ in relatively high concentrations during the first stage offers an indirect view of the reactions occurring during synthetic ASR pyrolysis. It is postulated that $\mathrm{HCl}$ released from PVC attacks N-containing polymers, such as polyurethane, to form quaternary cationic nitrogen species; this is followed by scission of the polymer chain through $\mathrm{CO}_{2}$ elimination, with subsequent formation of an olefinic end-group and an amine, as described earlier (8). The amine, most likely containing an $\mathrm{N}-\mathrm{CH}_{3}$ moiety (8), is further attacked by $\mathrm{HCl}$ to form a second, low-MW quaternary salt that decomposes to yield $\mathrm{CH}_{3} \mathrm{Cl}$.

To test the two-stage pyrolysis hypothesis, separate first- and second-stage pyrolysis experiments are under way. The products from each stage are recovered, and the residue from the first pyrolysis stage is used as starting material for the second. Preliminary results indicate that the first residue is about $75 \%$ by weight of the synthetic ASR charged. The first-stage liquids are mostly of the aqueous class: about $80-90 \%$ of the total $\mathrm{CO}_{2}$ is released, and more than $90 \%$ of the $\mathrm{CH}_{3} \mathrm{Cl}$ is released. Only very low levels of gaseous hydrocarbons form during the first stage. Most of the oxygen is removed in the first stage in the form of $\mathrm{CO}_{2}, \mathrm{CO}$, and $\mathrm{H}_{2} \mathrm{O}$, so secondary reactions of these inorganics with the residue are minimized (10). Therefore, second-stage pyrolysis yields primarily organic liquids and a gas rich in olefinic and paraffinic hydrocarbons.

A conceptual, two-stage ASR pyrolysis process that segregates the products from the two stages is envisioned. It could produce commodity methyl chloride in the first stage and valuable feedstock chemicals in the second stage. The potential for producing products from ASR pyrolysis more valuable than liquid fuel may thus be possible.

The above possibilities suggest a need to determine ASR pyrolysis kinetics experimentally. The smaller reactor system described in the experimental section was developed and operated for this purpose. In a universal reaction scheme that seems to fit the kinetic data, six universal reactions and five universal reactants and products in ASR pyrolysis are assumed: fresh ASR (F), gaseous products $(G)$, unvaporized liquids (L), solid residue (S), and condensed liquids (C). The sum of $F, L$, and $S$ (denoted as $R$ ) is retained in the reactor and monitored by the first transducer, $C$ is monitored by the second transducer, and the weight of gases is obtained by difference. The results of an early ASR pyrolysis run are graphically presented in Figure 4 . These results are correlated by the following simple scheme of universal reactions:

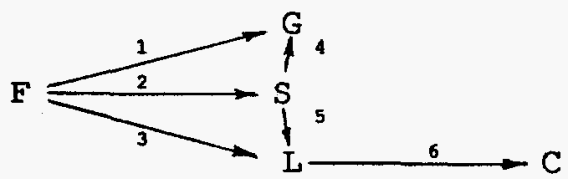

If reactions 1 through 6 are assumed to be Arrhenius-type first-order reactions, the kinetic model is simple and easily solved. The best-fit Arrhenius constants are given in the figure. The lines in the figure represent the best-fit model, and the points are from the experimental run. These results are consistent with the two-stage ASR pyrolysis hypothesis given above. Universal reactions 1,2 , and 3 with relatively low activation energies dominate the process initially at low temperatures. When higher temperatures are reached, reactions 4 and 5 become significant. Note that reaction 5, the production of liquids from solids, continues throughout the run, as evidenced by the mirror-image slopes of the $R$ and $L$ lines. Results like those presented in Figure 4 are currently being used to evaluate and develop conceptual commercial pyrolysis processes. A more detailed discussion of the kinetic model and its applications will be presented in a later paper.

\section{CONCLUSIONS}

The following conclusions, based on early but nevertheless solid experimental data, must be considered tentative, awaiting results from additional confirmatory experiments that are currentily under way:

1. Interaction of ASR components during pyrolysis modifies product distributions relative to single-component pyrolysis.

2. It is hypothesized that ASR pyrolysis occurs in two stages. The early, low-temperature stage $\left(300^{\circ} \mathrm{C}\right)$ produces mostly inorganic, light gases and high yields of methyl chloride and is susceptible to modification by catalysts. The later, high- temperature stage $\left(700^{\circ} \mathrm{C}\right)$ produces mostly organic liquids and gases and is less affected by the catalysts studied so far. Tests to identify catalysts effective in the second stage are under way.

3. Chlorine-containing compounds have not been found in ASR pyrolysis liquids. 
4. A universal reaction scheme based on first-order Arrhenius kinetics can be fit to ASR pyrolysis kinetic data and is consistent with the two-stage hypothesis.

5. The two-stage hypothesis increases the possibilities for devising two-stage commercial ASR pyrolysis processes that have improved economic potential.

\section{ACKNOWLEDGMENT}

This work was supported by the U.S. Department of Energy, Assistant Secretary for Energy Efficiency and Renewable Energy, under contract W-31-109-Eng-38.

The GC/MS analyses were done by the Analytical Chemistry Laboratory at Argonne National Laboratory.

\section{REFERENCES}

1. Automotive Engineering, August 1994, p. 29

2a. Day, M., Z. Shen, J.D. Cooney, Proc. Auto Recycle '94, p. 169

2b. Agarwar, K., SPE, Proc. "Plastics Recycling: Technology Charts the Course," Schaumburg, Ill., 1994, p. 232

2c. Tabery, R.S., Proc. Shredder Operations Conference, Austin, Texas, 1990, p. 1

3a. Proc. Auto Recycle '93, Schotland, Southfield, Mich.

3b. Proc. Auto Recycle '94, Schotland, Dearborn, Mich.

4. Compton, W.D., N.A. Gjostein, Joint Industry/University Research Programs, DOE Contract No. DE-AC02-78ER10049, May 15, 1984

5a. Pierce, A., Proc. Auto Recycle '92, p. 215

5b. Chambers, C., J.W. Larsen, W. Li, R. Wiesen, Ind. Eng. Chem. Process Res. Dev., $1984,23,648-654$

6. Roy, C., P. Mallette, Proc. Energy From Biomass and Wastes, IGT Conference XVI, 1992, p. 827

7. Flynn, J.H., R.E. Florin, "Pyrolysis and GC in Polymer Analysis," S.A. Liebman and

E.J. Levy, Eds., Marcel Dekker Inc., New York, p. 149

8. Rumao, L.P., K.C. Frisch, J. Pol. Sci., Part A-1, 10, 1499-1509 (1972)

9. O'Mara, M.M., J. Pol. Sci., Part A-1, 8, 1887-1899 (1970)

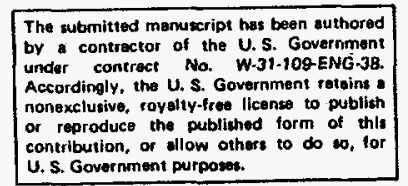

DISCLAIMER

This report was prepared as an account of work sponsored by an agency of the United States Government. Neither the United States Government nor any agency thereof, nor any of their employees, makes any warranty, express or implied, or assumes any legal liability or responsibility for the accuracy, completeness, or usefulness of any information, apparatus, product, or process disclosed, or represents that its use would not infringe privately owned rights. Reference herein to any specific commercial product, process, or service by trade name, trademark, manufacturer, or otherwise does not necessarily constitute or imply its endorsement, recommendation, or favoring by the United States Government or any agency thereof. The views and opinions of authors expressed berein do not necessarily state or reflect those of the United States Government or any agency thereof. 
TABLE 1: SYNTHETIC ASR

\begin{tabular}{|l|c|}
\hline \multicolumn{1}{|c|}{ COMPONENTS } & $\begin{array}{c}\text { AMOUNT PER AUN } \\
(\mathrm{g})\end{array}$ \\
\hline Wood & 6.7 \\
\hline $33 \%$ Glass Reinforced Polyester & 3.91 \\
\hline Tar & 3.35 \\
\hline Polyurethane Foam & 2.23 \\
\hline Polypropylene & 1.89 \\
\hline PVC & 1.55 \\
\hline ABS & 0.78 \\
\hline Nylon & 0.44 \\
\hline Acrylic TOTAL WEIGHT & 0.44 \\
\hline
\end{tabular}

TABLE 2: PYROLYSIS OF "SYNTHETIC" AUTOMOBILE SHREDDER RESIDUE - ASR

\begin{tabular}{|c|c|c|c|c|c|c|}
\hline \multirow[b]{2}{*}{ RUN No } & \multirow[b]{2}{*}{ CATALYST } & \multicolumn{5}{|c|}{ WEIGHT PERCENT OF PYROLYSIS PRODUCTS } \\
\hline & & $\begin{array}{l}\text { ORGANIC } \\
\text { LIQUIDS }\end{array}$ & $\begin{array}{c}\text { "AQUEOUS" } \\
\text { LIQUIDS }\end{array}$ & CHAR & GAS & $\begin{array}{c}\mathrm{CO}_{2} \\
\text { MAT. BAL. }\end{array}$ \\
\hline 1 & NONE & 8.1 & 15.3 & 33.2 & 43.4 & 6.2 \\
\hline 2 & NONE (tast t-ramp) & 6.7 & 15.5 & 33.1 & 44.7 & 8.1 \\
\hline 3 & NONE (w/o PVC) & 6.7 & 16.1 & 32.2 & 45.0 & 9.1 \\
\hline 4 & $\mathrm{MgO}-\mathrm{ZnO}$ & 9.5 & 22.3 & 24.4 & 43.8 & ND \\
\hline 5 & $\mathrm{MgO}-\mathrm{ZnO}$ & 9.7 & 22.4 & 23.9 & 44.0 & ND \\
\hline 6 & ZnO-TiO, & 10.2 & 18.1 & 27.1 & 44.6 & ND \\
\hline 7 & ZnO-TiO, & 8.9 & 18.9 & 23.5 & 48.7 & 13.4 \\
\hline 8 & $\mathrm{TiO}_{2}-\mathrm{SiO}_{2}$ & 8.8 & 18.2 & 27.2 & 45.8 & ND \\
\hline 9 & $\mathrm{ZnO}-\mathrm{Al}_{2} \mathrm{O}_{3}$ & 9.5 & 20.0 & 24.7 & 45.8 & ND \\
\hline 10 & $\mathrm{MgZrO}$ & 7.7 & 14.2 & 32.1 & 46.0 & ND \\
\hline 11 & MgTiO, & 8.2 & 14.4 & 32.1 & 45.3 & ND \\
\hline 12 & $\mathrm{Fe}, \mathrm{O}$ & 9.7 & 15.3 & 31.9 & 43.1 & 18.2 \\
\hline 13 & CuO & 7.7 & 16.9 & 27.5 & 47.9 & 11.7 \\
\hline 14 & Montmorillonite K 10 & 8.8 & 17.1 & 30.4 & 43.7 & 6.6 \\
\hline 15 & ASR Char & 7.2 & 14.9 & 31.6 & 46.3 & 8.9 \\
\hline
\end{tabular}

TABLE 3. COMPOSTION OF QASES (PEA CEIT) OY CC - FIABT SAMPLE

\begin{tabular}{|c|c|c|c|c|c|c|c|c|c|c|c|}
\hline FUNNo. & CATALYST & TEMP. IC & Methene & Elhylene & Elhene & Propylene & $\begin{array}{l}\text { Methyl } \\
\text { Chioride }\end{array}$ & Butene & Butediene & Unknown & Unknown 2 \\
\hline 1 & NONE & 400 & $\overline{3.3}$ & 1.5 & 1.5 & 2.8 & 87.4 & 3.0 & 0.0 & 0.4 & 0.0 \\
\hline 2 & NONE (fast t-ramp) & 400 & 3.6 & 1.5 & 1.5 & 2.8 & 87.8 & 2.6 & 0.0 & 0.0 & 0.0 \\
\hline 3 & NONE (w/O FVC) & 416 & 22.9 & 10.8 & 9.7 & 25.0 & 4.7 & 11.9 & 2.6 & 0.6 & 0.0 \\
\hline 4 & $M g O-Z n O$ & 439 & 9.3 & 10.3 & 9.6 & 34.3 & 12.0 & 8.8 & 1.3 & 6.5 & 4.6 \\
\hline $\bar{E}$ & MeO-ZnO & 400 & 7.2 & 5.5 & 5.1 & 17.2 & 46.1 & 6.74 & 1.5 & 8.1 & 0.0 \\
\hline 6 & $\mathrm{ZnO}-\mathrm{TKO}$ & 414 & 5.4 & 5.8 & 5.5 & 17.6 & 35.2 & 7.8 & 0.0 & 8.7 & 0.0 \\
\hline 7 & Zno-Tio, & 410 & 5.7 & 4.9 & 5.0 & 20.5 & 53.3 & 6.3 & 2.0 & 0.0 & 0.0 \\
\hline 8 & Tio, -510 & 410 & 8.3 & 4.6 & 4.6 & 16.5 & 52.8 & 5.0 & $0 . \overline{7}$ & 7.6 & 0.0 \\
\hline 8 & $2 n O-A 1, O$ & 400 & 4.5 & 4.6 & 4.2 & 12.4 & 56.2 & 7.6 & 2.1 & 5.0 & 0.0 \\
\hline 10 & $\mathrm{MgZrO}$ & 438 & 8.7 & 8.2 & 7.9 & 37.4 & 13.5 & 9.0 & 0.1 & 8.5 & 4.8 \\
\hline 11 & $\mathrm{MgTKO}$ & 400 & 6.1 & 3.9 & 3.6 & 13.5 & 57.9 & 6.4 & 0.7 & 5.8 & 0.0 \\
\hline 12 & $\mathrm{Fe}, \mathrm{O}$, & 410 & 7.2 & 14.2 & 14.2 & 19.7 & 36.7 & 5.1 & 0.8 & 0.7 & 0.0 \\
\hline $\mathbf{1 3}$ & CuO & $\$ 00$ & 8.5 & 7.0 & 6.3 & 41.5 & 28.6 & 6.3 & 1.0 & 0.9 & 0.0 \\
\hline 14 & Montmorillonile K 10 & 400 & 3.0 & 3.8 & 3.6 & 4.8 & 82.0 & 2.7 & 0.0 & 0.0 & 0.0 \\
\hline 15 & ASAC Cher & 400 & 2.8 & 1.5 & 1.2 & 2.5 & 90.4 & 1.6 & 0.0 & 0.0 & 0.0 \\
\hline
\end{tabular}

TABLE 4. GC ANALYSIS OF THE SECOND AND THIRD GAS

SAMPLES, AT $500^{\circ} \mathrm{C}$ AND $650^{\circ} \mathrm{C}$, AESPECTIVELY. STATISTICAL

DISTRIBUTION OF PRODUCTS FROM RUNS 1 - 15

\begin{tabular}{|l|c|c|c|c|}
\hline GASES & \multicolumn{2}{|c|}{ SECOND SAMPLE } & \multicolumn{2}{c|}{ THIRD SAMPLE } \\
& MEAN (\%) & STANDARD DEVIATION & MEAN (\%) & STANDARD DEVIATION \\
\hline Methane & 14.3 & 1.39 & 41.5 & 2.08 \\
\hline Ethylene & 9.7 & 2.15 & 11.9 & 1.05 \\
\hline Ethane & 13.6 & 0.71 & 13.25 & 1.43 \\
\hline Propylene & 32.5 & 2.16 & 19.25 & 1.87 \\
\hline Methyl Chloride & 2.33 & & 0.52 & \\
\hline Butene & 12.6 & 1.55 & 8.59 & 0.88 \\
\hline Butadiene & 0.21 & & 2.27 & \\
\hline Unknown 1 & 4.32 & & 0.5 & \\
\hline Unknown 2 & 8.95 & & 0.35 & \\
\hline
\end{tabular}



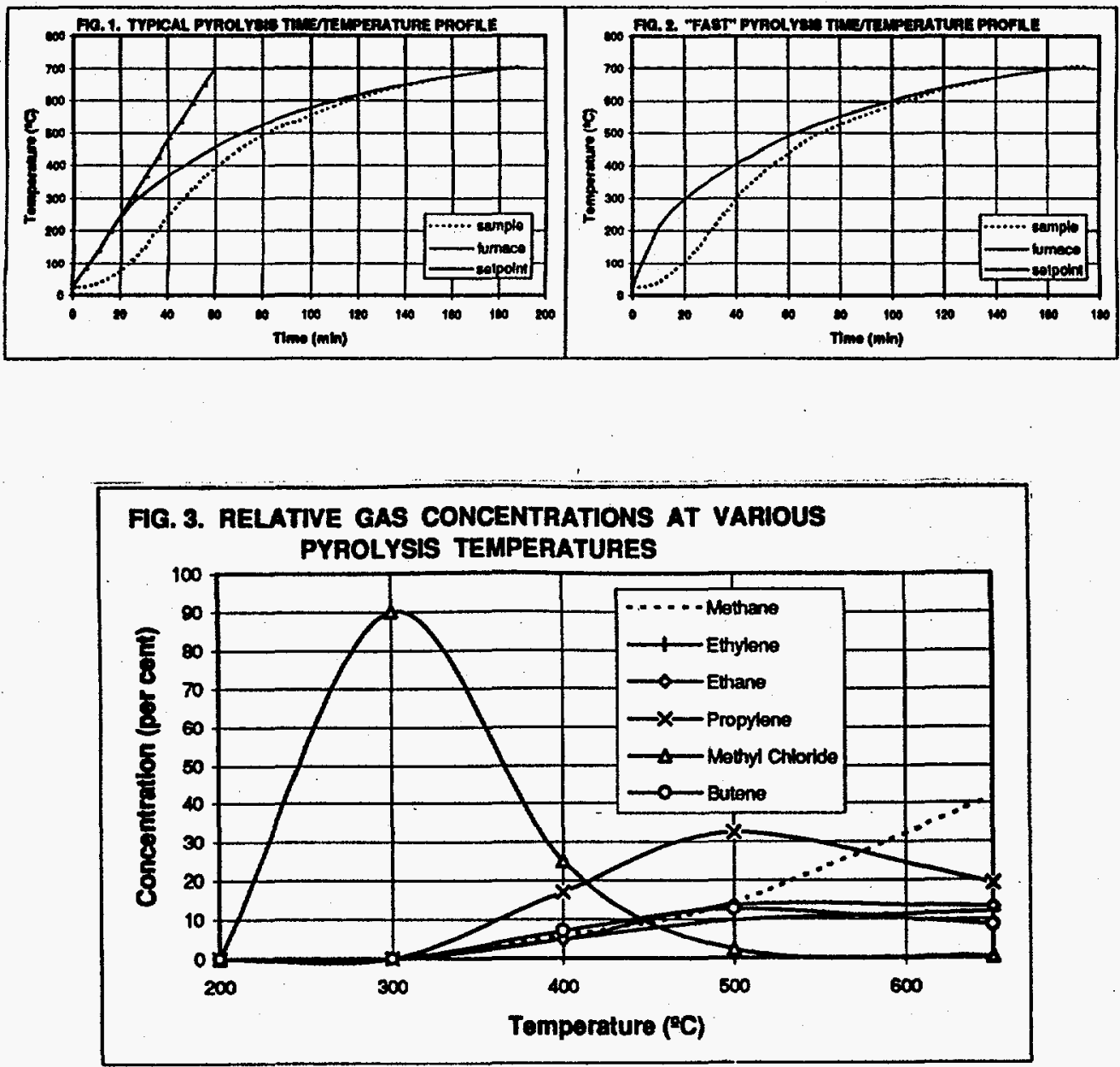

FIG. 4. ASR PYROLYSIS DATA (POINTS) AND MODEL (LINES)

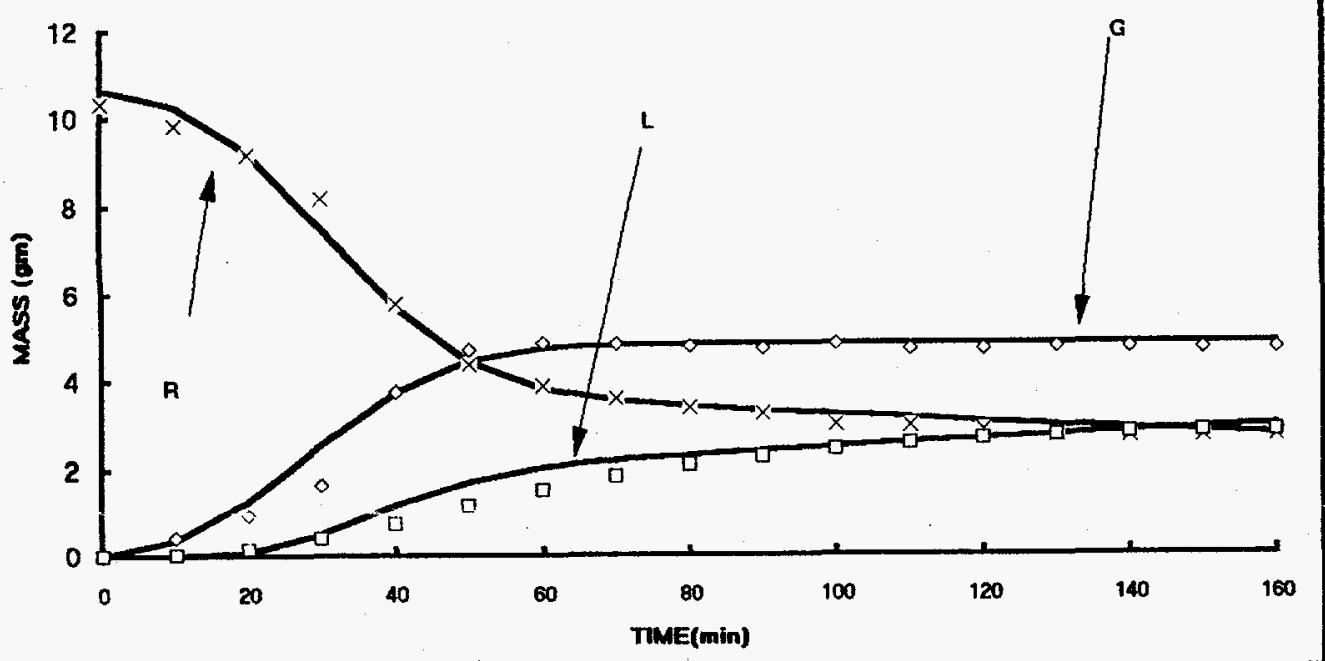

\begin{tabular}{|c|c|c|}
\hline REACTION & ACTIVATION ENEROY (cal/molo) & PRE-EXPONENTIAL ( $(1 / \mathrm{mm})$ \\
\hline 1 & 3000 & 0.13 \\
\hline 2 & 3000 & 0.10 \\
\hline 3 & 5500 & 0.14 \\
\hline 4 & 14000 & 0.004 \\
\hline 5 & 7000 & 0.08 \\
\hline 6 & 5000 & 10.0 \\
\hline
\end{tabular}

